\title{
ISONIAZID ALONE AND COMBINED WITH THIOSEMICARBAZONE
}

\section{W. S. Davidson, M.B., CH.B., D.P.H.}

In a previous paper(1) I described how a small series of cases improved at the end of six months on INH; improved at a slower rate for the next three months and then deteriorated when the INH was combined with sulphetrone. These cases improved again when put on INH alone.

Subsequent follow-up has, however, indicated that this improvement was not maintained. Consequently, a further series of II cases has been tested on INH alone. At the end of six months the group improvement index, calculated by awarding marks for clinical and bacteriological improvement as previously described(2) was 0.36 . By the end of twelve months, however, this index had fallen to o.I8. Three cases had improved, three were worse than when treatment started and five had not altered.

To whatever extent conclusions are justified on such small series of cases; it would appear that INH produces its maximum improvement between the sixth and ninth month of treatment and 
thereafter the cases deteriorate, presumably from the development of resistance. The onset of resistance may be delayed by the exhibition of other anti-leprosy drugs.

As a pilot series of INH and Thiosemicarbazone ${ }^{(1)}$ had shown more promise than INH and sulphetrone, 47 cases were put on the combined treatment of INH and Thiosemicarbazone (Neustab).

These 47 patients were all suffering from lepromatous leprosy of considerable duration. They had all had previous extensive treatment with sulphones and some also with thiosemicarbazone. They had reached a stage of chronicity in their disease where no further improvement appeared to be taking place.

The result of ten months' treatment with combined INH and Thiosemicarbazone (Neustab) is shown in the table.

The two fatal cases have been ignored when calculating the index of progress. They died during a severe influenza epidemic and the mortality in the series was not significantly different from the general mortality in the leprosarium at that time. Their deaths were not in any way attributable to the treatment and they were improving up to the time of their fatal illness.

Considering the chronicity of the disease in all cases and the lack of further improvement in previous treatments, the index of progress of $\mathrm{I} .42$ must be considered as very good. Eleven cases became bacteriologically negative, a further 22 cases showed improvement, ten cases remained static and two cases deteriorated. Several cases shown as static in actual fact show improved smears but the improvement is not yet sufficient to be recorded in our counting system.

It will be noted that the improvement in cases not previously treated with thiosemicarbazone is slightly greater than those so previously treated. An element of the total improvement is therefore due to the Neustab alone, but there is a substantial improvement in the cases previously treated with Neustab suggesting that the combination of INH and Neustab had remedial properties over and above the mere summation of the effects of the individual drugs.

The daily adult dosage was $350 \mathrm{mg}$. INH and $200 \mathrm{mg}$. Neustab. This dosage was reached in suitable cases in 2 months. It was given for six days a week and there was a week's rest after every two months' treatment.

The dosage, however, requires careful adjustment to the reaction of the patient and can only be given to patients under constant supervision. In all, 22 cases suffered from toxic or reactive phases requiring a break or modification of treatment. 
The main clinical impressions are that INH increases the incidence of neuritic reactions and thiosemicarbazone produces an anaemia which is slower in recovery than that associated with sulphone treatments.

In the 22 toxic cases, there were eight cases of neuritis and fourteen of anaemia. Several also suffered from dermatitis, albuminuria, pyrexia, and erythema nodosum.

Toxic manifestations occasionally required cessation of treatment but in general modification of dosage was sufficient.

\section{Summary and CONClusion}

The present paper continues a previous examination and report on the use of INH alone and in combination with other anti-leprosy drugs.

There are indications that INH alone reaches its maximum usefulness between the sixth and ninth month of exhibition and thereafter cases fail to improve, or deteriorate.

INH and sulphetrone in a small series did not show good results.

INH and thiosemicarbazone (Neustab) in a series of 47 cases gave very promising results over a Io-month period.

INH plus thiosemicarbazone in full dosages may give rise to toxic manifestations. This treatment should therefore be given in an institution under medical supervision.

\section{Table Showing Result of Ten Month's Treatment of INH aNd Neustab}

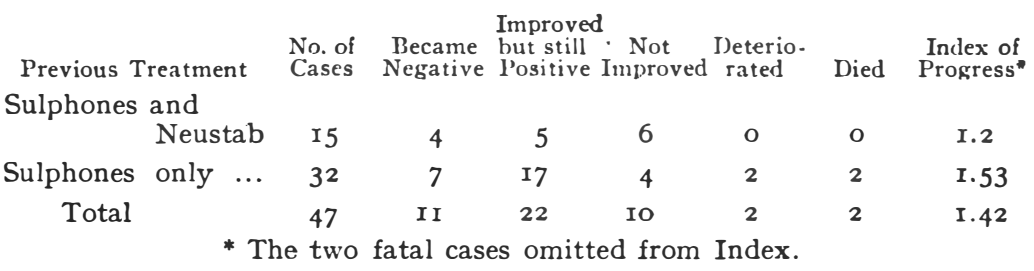

\section{ACKNOWLEDGEMENTS}

The above patients are inmates of Derby Leprosarium. To Dr. Peter Graham, Mother Alphonsus and Staff of that institution I am indebted for the daily care of the patients and the maintenance of records forming the basis of this paper.

\section{REFERENCES}

(1) W. S. DAvidson. "Isoniazid Alone and in Combination with Other Drugs in the Treatment of Leprosy." Leprosy Review, XXV, 69, 1954.

(2) W. S. DAvidson. "Evaluation of New Treatments." Leprosy Review, XXIV, 139, 1953. 